\title{
Neuropsychological correlates of recollection and familiarity in normal aging
}

\author{
PATRICK S. R. DAVIDSON and ELIZABETH L. GLISKY \\ University of Arizona, Tucson, Arizona
}

\begin{abstract}
The dual-process model of recognition memory proposed by Jacoby (1991; see also Mandler, 1980) postulates the existence of two independent components of recognition memory: a conscious retrieval process (recollection) and an automatic component (familiarity). Older adults appear to be impaired in recollection, but findings with respect to familiarity have been mixed. Studies of the brain bases of these components, using neurological patients, have also been inconclusive. We examined recollection and familiarity, using the process dissociation procedure, in older adults characterized on the basis of both their frontal and their medial temporal lobe function. Findings suggest that only some older adults, depending on their neuropsychological status, are impaired in recollection and/or familiarity: Recollection seems to involve both frontal and medial temporal lobe function, whereas familiarity appears to be dependent only on function associated with the medial temporal lobes.
\end{abstract}

In 1980, Mandler noted that retrieval of context may be important for recognition memory, in order that a feeling of familiarity be attributed to its correct source and thereby specified more precisely. Other researchers have concurred and postulated that two separate processes, recollection and familiarity, may be involved in recognition memory (Atkinson \& Juola, 1974; Jacoby, 1991; Jacoby \& Dallas, 1981). Recollection is said to occur when contextual details about a previous experience are retrieved. In contrast, familiarity is thought to be based primarily on the processing of an item's perceptual characteristics (Jacoby, Jennings, \& Hay, 1997; Jacoby, Yonelinas, \& Jennings, 1997; Mandler, 1980). Usually, both processes contribute to memory. Sometimes, however, people may choose to rely only on familiarity, or recollection may fail, so that the feeling of familiarity cannot be assigned to its appropriate source.

When older adults make errors in recognition memory, their errors often appear to reflect an overreliance on feelings of familiarity and/or a failure to retrieve context-specific information. Although familiarity-based recognition judgments may be accurate under some conditions, under other

This paper is based on the first author's master's thesis, submitted to the University of Arizona. A preliminary report was presented at the 41st Annual Meeting of the Psychonomic Society in New Orleans, 2000. Support was provided by Grant AG 14792 to E.L.G. from the National Institute on Aging and by a fellowship to P.S.R.D. from the Natural Sciences and Engineering Research Council of Canada. Kelly Murray and Jason Worrell provided assistance. We thank Gordon Logan for the Stop Signal program and Andrew Yonelinas for the algorithm used in the process dissociation analyses. Janine Jennings gave helpful advice at the beginning of this project, as did Lee Ryan and Cyma Van Petten throughout the research process. Correspondence should be sent to P.S.R. Davidson, Department of Psychology, University of Arizona, Tucson, AZ 85721-0068.(e-mail: pdavidso@u.arizona.edu). conditions, recollective processes are necessary for correct recognition decisions. In these cases, older adults are more prone to error than are young adults. For example, in the false-fame paradigm used by Jacoby and colleagues (e.g., Dywan \& Jacoby, 1990; Multhaup, 1995), people studied a list of names that they were told were nonfamous (e.g., Sebastian Weisdorf). At test, they were asked to identify the names of famous people from among the studied nonfamous names, new nonfamous names, and the names of people who were actually famous (e.g., Roger Bannister). Older people often mistakenly identified the studied nonfamous names as famous, arguably because these names seemed familiar but their recent occurrence in the study list was not recollected.

In order to differentiate between recollection- and familiarity-based memory judgments, Jacoby (1991) designed an extension of the false-fame paradigm, which he called the process dissociation procedure (PDP). In the simplest version of the task, participants study groups of items at two different points in time, followed by two test phases. During the inclusion phase, people include in recognition all previously studied items, no matter when those items occurred. In this case, recollection and familiarity act in harmony to produce successful recognition. If the two processes are independent, as Jacoby (Jacoby, Yonelinas, \& Jennings, 1997) has argued, the probability of saying "yes" to a given target in the inclusion condition is dependent on recollection, $R$, and on familiarity in the absence of recollection, $F(1-R)$, and can be represented by the equation $P$ ("yes" $\mid$ old $)_{\text {inc }}=R+F(1-R)$.

In the exclusion phase, people must exclude items from one of the two lists. The items to be excluded are familiar because of recent presentation, but their endorsement will produce an error. Only recollection of the list in which an item appeared at study will result in a successful exclusion judgment. Thus, in exclusion, recollection and familiarity act in 
opposition. The probability of making an exclusion errorof saying "yes" to an old item that is to be excluded-can be represented as $P$ ("yes" $\mid$ old $)_{\mathrm{exc}}=F(1-R)$, the probability that an item is familiar but its occurrence on the exclusion list cannot be recollected. As was noted above, the difference in performance between inclusion and exclusion may be used to derive an index of recollection [i.e., $R=P(\text { "yes" } \mid \text { old })_{\text {inc }}-P(\text { "yes" } \mid \text { old })_{\text {exc }}$ ], and familiarity can be calculated by solving the equations for $F$. The PDP model assumes that familiarity and recollection are two independent processes, and although this assumption has been challenged (e.g., Dodson \& Johnson, 1996; Graf \& Komatsu, 1994; Joordens \& Merikle, 1993; Ratcliffe, Van Zandt, \& McKoon, 1995), the two-process model continues to provide a viable theoretical account of recognition memory and offers a reasonable explanation for a substantial number of empirical findings (e.g., Jacoby, 1999; Jacoby, Yonelinas, \& Jennings, 1997).

In the present paper, we propose to examine recollection and familiarity in older adults and to explore the neuropsychological correlates of age-related differences in these two processes. In PDP studies of aging, recollection has generally been found to be impaired in older adults (Hay \& Jacoby, 1999; Jennings \& Jacoby, 1993, 1997; Rybash \& Hoyer, 1996; Rybash, Santoro, \& Hoyer, 1998; Salthouse, Toth, Hancock, \& Woodward, 1997; SchmitterEdgecombe, 1999; Titov \& Knight, 1997; for a review, see Light, Prull, La Voie, \& Healy, 1999). The evidence concerning familiarity, on the other hand, is equivocal. Many PDP studies have reported no effect of aging on the measure of familiarity (Hay \& Jacoby, 1999; Jennings \& Jacoby, 1993, 1997; Salthouse et al., 1997; Titov \& Knight, 1997), but other studies have found reduced familiarity with age (Light et al., 1999; Rybash et al., 1998; SchmitterEdgecombe, 1999). Individual differences among older adults with respect to brain aging may explain the mixed findings regarding familiarity in the literature on aging.

So far, there is relatively little information concerning the brain regions supporting recollection and familiarity. Studies of memory-impaired patients in which the PDP has been used have generally not been very informative in this respect. Although most studies have reported impaired recollection and intact familiarity (Cermak, Verfaellie, Sweeney, \& Jacoby, 1992; Christensen, Kopelman, Stanhope, Lorentz, \& Owen, 1998; Kazes et al., 1999; Mayes, Van Eijk, \& Isaac, 1995; Scarrabelotti \& Carroll, 1999; Ste-Marie, Jennings, \& Finlayson, 1996; Verfaellie, 1994; Verfaellie \& Treadwell, 1993), patient etiologies have been too variable to permit strong conclusions concerning the neural underpinnings of the two processes. Both the frontal lobes (FLs) and the medial temporal lobes (MTLs) have been hypothesized to play a role. Furthermore, Yonelinas, Kroll, Dobbins, Lazzara, and Knight (1998) have suggested that different structures within the MTLs may support recollection- and familiarity-based recognition judgments. They tested three amnesic patients, all of whom had suffered cerebrovascular accidents in the left MTL region that affected both the hippocampus and the adjacent cortex. These patients exhibited a decrease in recollection and a smaller but still significant decrease in familiarity. Drawing on evidence presented by Aggleton and Brown (1999; see also Aggleton \& Shaw, 1996) that amnesic patients without damage to the perirhinal cortex exhibited intact recognition memory, Yonelinas et al. (1998) suggested that familiarity may depend on the perirhinal cortex or other neocortical structures in the medial temporal region, whereas recollection may depend critically on the hippocampus.

Other investigators have hypothesized FL involvement in recollection (e.g., Dorfman et al., 1998; Jennings \& Jacoby, 1997; Toth \& Hunt, 1998), and one study has shown impaired recollection in patients with focal FL lesions (Hay, Moscovitch, \& Levine, 2002). There is additional evidence that executive function, usually thought to be dependent on the FLs, is important for recollection. Scarrabelotti and Carroll (1999) found correlations between recollection and both Stroop performance and California Verbal Learning Test (CVLT) semantic clustering (Delis, Kramer, Kaplan, \& Ober, 1987), two measures thought to reflect executive function. Salthouse et al. (1997) found a relationship between recollection and two other measures of FL function, phonemic fluency and trail making (Reitan, 1992), although recollection was also correlated with performance on other tests not strongly associated with FLprocesses, including letter and pattern comparison and vocabulary.

There may be a more specific reason for hypothesizing that recollection is supported at least partly by the FLs. Successful exclusion depends in part on remembering source - the spatial, temporal, or perceptual context in which one encounters a particular item (e.g., Buchner, Steffens, Erdfelder, \& Rothkegel, 1997; Graf \& Komatsu, 1994; Mulligan \& Hirshman, 1997; Roediger \& McDermott, 1994; Steffens, Buchner, Martensen, \& Erdfelder, 2000; Verfaellie \& Treadwell, 1993). For example, in the list discrimination PDP paradigm, participants must remember not only a target, but also the list from which the target came. In general, FL damage impairs memory for source, including memory for temporal order (Butters, Kaszniak, Glisky, Eslinger, \& Schacter, 1994; Johnson, O'Connor, \& Cantor, 1997; Kesner, Hopkins, \& Fineman, 1994; Kopelman, Stanhope, \& Kingsley, 1997; McAndrews \& Milner, 1991; Parkin, Leng, Stanhope, \& Smith, 1988; Swain, Polkey, Bullock, \& Morris, 1998), even when item memory is unaffected by the lesion or is equated between patients and controls (Mangels, 1997; Milner, Corsi, \& Leonard, 1991; Shimamura, Janowsky, \& Squire, 1990). The lesion data are further supported by functional neuroimaging studies, which have implicated the frontal cortex in temporal order memory (Cabeza, Anderson, Houle, Mangels, \& Nyberg, 2000; Cabeza et al., 1997, 2000; Nyberg et al., 1996).

Older adults appear to show preferential declines in the structure and function of the FLs with advancing age, al- 
though other structures, including regions of the MTLs, may also be affected (for a review, see Raz, 2000). Not surprisingly, then, many older adults are more impaired in memory for the temporal context of an event than for its content (e.g., Fabiani \& Friedman, 1997; Kliegl \& Lindenberger, 1993; Parkin, Walter, \& Hunkin, 1995; for a review, see Spencer \& Raz, 1995). Not all older adults experience this selective impairment of source memory, however, nor do they show equivalent FL decline. Those with low FL function appear to be particularly vulnerable to deficits in source memory (Craik, Morris, Morris, \& Loewen, 1990; Glisky, Polster, \& Routhieaux, 1995; Glisky, Rubin, \& Davidson, 2001; Mather, Johnson, \& De Leonardis, 1999), including list discrimination (Fabiani \& Friedman, 1997; Parkin et al., 1995).

The frontal lobes may be implicated in recollection for another reason. Several researchers have suggested that, like frontal patients, older adults show a decrease in the ability to inhibit irrelevant or no longer relevant information from memory (for a review, see Zacks, Hasher, \& Li, 1999). If, in the PDP, older adults are unable to inhibit feelings of familiarity arising from recent exposure, the recollective process may be prevented from taking precedence, resulting in increased exclusion errors. This inhibitory problem may be particularly pronounced in older adults with reduced FL function. Finally, it may be that initiating the recollective process requires frontal control, whereas familiarity occurs automatically. Older adults with declining FL abilities may fail to initiate the appropriate retrieval processes and may simply rely on the less demanding familiarity process.

A strategy that we have used to examine source memory in aging involves comparing young people with different subgroups of older adults, who are divided on the basis of their neuropsychologicalfunction. Glisky et al. (1995) performed a factor analysis of tests conducted on healthy older adults and uncovered two orthogonal factors: One factor consisted of tests traditionally thought to depend preferentially on FL function (perhaps on working memory), whereas the other factor consisted of long-term memory measures, thought to reflect primarily MTL function. When older adults were categorized according to whether they were high or low on the aggregate measure of FL function, only those older adults with below-average FL scores were impaired in source memory, as compared with young people (Glisky et al., 2001).

\section{THE PRESENT STUDY}

In the present study, we used these same composite measures of FL and MTL function. If recollection is dependent on the same processes that support source memory, older adults with low FL scores (and correspondingly poor source memory) should be impaired in recollection, relative to young people. Recollection may also be dependent on the MTLs, as was suggested by Aggleton and Brown (1999) and Yonelinas et al. (1998). Familiarity, on the other hand, may occur automatically without frontal control, relying instead on structures in the MTL region (Aggleton \& Brown, 1999; Yonelinas et al., 1998). ${ }^{1}$

Alternatively, exclusion errors and low recollection scores may occur as a result of inhibitory failure (Graf \& Komatsu, 1994; Zacks et al., 1999). The current aggregate score of FL function does not include tests thought primarily to measure inhibition. To test the possibility that older adults' impaired performance on the PDP is attributable to a failure to inhibit the familiarity process, we included additional inhibitory tasks in the present study. Correlations between inhibitory measures and exclusion error rates or recollection would support a role for inhibition in the exclusion process.

We used a list discrimination design similar to that employed by Titov and Knight (1997), which involved an incidental study phase with two lists of words, followed by two test phases. In the inclusion test, the participants were merely asked to identify all studied items. In the exclusion test, they were required to identify the items from one list and to exclude those from the other list. The paradigm was difficult enough to ensure that all the participants made exclusion errors, but not so difficult that people were unable to perform the task. PDP instructions are potentially confusing for older adults (Graf \& Komatsu, 1994); to ensure that the instructions did not introduce a confound into the experiment, we kept them in the participants' view during both tests and ensured, during debriefing, that all the participants had understood what they were to do.

\section{METHOD}

\section{Participants}

Thirty-two young adults (age, $18-26$ years, $M=20.17$ years, 20 females) were recruited from undergraduate introductory psychology classes at the University of Arizona and were awarded course credit for participation. They had normal or corrected-to-normal vision and hearing, were not using psychotropic medication, and were free of learning and reading impairments. The results of 10 additional young adults were discarded: 9 because they did not meet our inclusion criteria and 1 because of a procedural anomaly.

Forty-eight older adults (age, $65-85$ years, $M=73.88$ years, 30 females) were selected from our participant list and were paid $\$ 6$ per hour to participate. All were community-dwelling, had normal or corrected-to-normal vision and hearing, and were free of neurological or psychiatric illness, including depression and dementia. None reported drug or alcohol abuse. The results of 4 additional older participants were discarded: 3 failed to meet the inclusion criteria, and 1 clearly misunderstood the PDP instructions. Both age groups had college-level education, although the older adults were better educated than the young people $[M=15.25$ and 13.28 years, respectively; $t(78)=3.73, p<.001]$.

The older adults had previously undergone extensive neuropsychological testing within 25 months of the present experiment. The results were used to create two composite $z$ scores for each older participant on the basis of tests that loaded together on a factor analysis of a group of 100 older adults. The analysis revealed two orthogonal factors (Glisky et al., 1995; see also Henkel, Johnson, \& De Leonardis, 1998). One was thought to reflect FL function and was based on five measures: the number of categories achieved on a modified Wisconsin Card Sorting Test (Hart, Kwentus, Wade, \& Taylor, 1988), the total 
number of words produced to the cues $F, A$, and $S$ in a phonemic fluency test (Spreen \& Benton, 1977), the Mental Arithmetic subtest from the Wechsler Adult Intelligence Scale-Revised (WAIS-R; Wechsler, 1981), and the Backward Digit Span and Mental Control measures from the Wechsler Memory Scale-Revised (WMS-R; Wechsler, 1987). The other composite measure was thought to reflect MTL function and consisted of four scores: Logical Memory I, ${ }^{2}$ Verbal Paired Associates I, and Visual Paired Associates II (subtests of the WMS-R), and the Long Delay Cued Recall score from the CVLT (Delis et al., 1987). Those participants with $z$ scores for the FL measure below the normative group mean were classified as the low-FL group, whereas those with $z$ scores above the normative group mean formed the high-FL group. The same procedure was used to categorize the older adults in terms of MTL function (Glisky et al., 1995).

Table 1 shows demographic variables and composite neuropsychological measures by neuropsychological group. Separate $2 \times 2$ between-subjects analyses of variance (ANOVAs), with FL (high/ low) and MTL (high/low) status as variables, revealed that the highFL and the low-FL groups differed significantly on the FL battery score, as was expected $\left[F(1,44)=110.39, M S_{\mathrm{e}}=0.08, p<.001\right]$, but not on the MTL score $\left[F(1,44)=1.36, M S_{\mathrm{e}}=0.08\right]$, whereas the high-MTL and the low-MTL groups differed on the MTL measure $\left[F(1,44)=133.68, M S_{\mathrm{e}}=0.10, p<.001\right]$, and not on the FL score $(F<1)$. There were no significant interactions between factors. The four neuropsychological groups were equivalent on the demographic variables listed in Table 1 , as was indicated by separate $2 \times 2$ between-subjects ANOVAs, all of which were nonsignificant.

\section{Materials}

Ninety-six concrete nouns were chosen from the Francis and Kučera dictionary (1982) and were divided into four lists of 24 words. Half the words in each list were high frequency (greater than 100 occurrences per million), and half were low frequency (fewer than 10). Word length was matched between lists, so that each list contained the same number of four-letter, five-letter, and six-letter nouns. Two of the lists were randomly chosen to be study lists, whereas the other two lists were designated distractor lists. Two words were added to the beginning of each study list, and 2 words were added to the end, in order to absorb primacy and recency effects. All the target words were presented at test, half from each study list in the inclusion task and the other half in the exclusion task. Both the inclusion task and the exclusion task also included 24 distractors; thus, both the inclusion and the exclusion tests consisted of 24 studied words (12 from each study list) and 24 new words

An additional six tests, thought to measure inhibitory function, were administered to the older participants. These measures were chosen a priori on the basis of the fact that all involved inhibiting a more dominant response (e.g., reading a word) in favor of a less dominant one (e.g., naming the color ink in which the word was printed). The concept of inhibition may not be unitary, however, and intercorrelations among different inhibitory measures are often low (e.g., Kramer, Humphrey, Larish, \& Logan, 1994). In addition, these tasks may measure more than one kind of process (e.g., inhibition vs. task switching or other related functions) to greater or lesser degrees. We therefore consider their use exploratory.

Visual Verbal Test. Ten cards, each containing four drawings, were shown one at a time to participants (Feldman \& Drasgow, 1981). Three of the four drawings on each card were alike in some way (e.g., color), and a different set of three objects on the card were alike in some other way (e.g., orientation). The participants were required to identify one set of three items and say how they were alike, and then do the same for the second set, within 2 min. Inhibition on this task was measured by the ability to switch from the first set of three items to the second, divided by the total number of correct solutions.

Release from proactive interference. Lists of concrete nouns were derived from one of four categories (animals, tools, food, and clothing). Words from the same category were grouped together and read aloud to the participants in several consecutive sets of three (e.g., horse, deer, rabbit; followed by donkey, lion, sheep). After each set of words, the participants counted backwards aloud for $9 \mathrm{sec}$ and were then asked to recall the items. After several sets (either four or five), the words switched to a new category (e.g., tools). Two scores were calculated. Proactive interference (PI) was based on the mean difference between the number of words correctly recalled on the first and last sets of a category (e.g., animals). Release from PI was calculated by using the mean difference in the number of words correctly recalled on the last set of one category (e.g., animals) and the first set of the following category (e.g., tools).

Stroop Neuropsychological Screening Test. This version of the Stroop test (Trenerry, Crosson, DeBoe, \& Leber, 1989) consisted of two lists of color names: tan, red, blue, and green. The print ink of each color name was different from the name itself (e.g., the word tan could be printed in red, blue, or green ink). In each list, words were repeated 28 times and were randomly mixed in four columns on a piece of paper. On the first list, the participants read the words aloud as quickly as possible. On the second list, they named the color of ink in which the names were printed, ignoring the color names themselves. In both cases, the participants were asked to go as quickly as possible but to correct themselves if they made an error. Interference was measured by calculating the difference between the rate at which the participants read the words on the first list and the rate at which they named the color of ink on the second list.

Trail Making Test. The participants used a pen to connect a series of circles in consecutive order as quickly as possible on a page; if they made an error, they were to correct themselves. On the first

Table 1

Characteristics of Older Adults by Neuropsychological Group FL Function

\begin{tabular}{lccccc}
\hline & \multicolumn{4}{c}{ Functions } \\
\cline { 2 - 3 } \cline { 5 - 6 } & \multicolumn{2}{c}{ High FL } & & \multicolumn{2}{c}{ Low FL } \\
\cline { 2 - 3 } \cline { 5 - 6 } & High MTL & Low MTL & & High MTL & Low MTL \\
\hline$n$ & 12 & 12 & & 12 & 12 \\
Age (years) & 76.13 & 73.92 & & 72.31 & 73.19 \\
PIQ & 119.58 & 113.83 & & 113.67 & 109.25 \\
Education (years) & 14.58 & 16.25 & & 15.33 & 14.83 \\
MMSE (/30) & 28.92 & 28.67 & & 28.83 & 28.50 \\
FL score & .50 & .37 & & -.42 & -.48 \\
MTL score & .64 & -.62 & & .44 & -.45 \\
\hline
\end{tabular}

Note-FL, frontal lobe; MTL, medial temporal lobe; PIQ, performance IQ from the Wechsler Adult Intelligence Scale-III (Wechsler, 1997a) or the Wechsler Abbreviated Scale of Intelligence (1999); MMSE, Mini Mental Status Exam (Folstein, Folstein, \& McHugh, 1975). See the text for an explanation of FL and MTL scores. 
page, the participants connected a series of numbers (i.e., 1 to 2 to 3 , etc.). On the second page, they alternated between numbers and letters (i.e., $l$ to $A$ to 2 to $B$, etc.). Scoring was based on the difference in time required to complete the first and the second pages (see Lezak, 1995).

Hayling test. The participants were read sentences that were missing the last word (e.g., The captain wanted to stay with the sinking. ..) and were asked to complete the sentence as quickly as possible (Burgess \& Shallice, 1996, 1997). In the first part of the test, the participants were to provide a word that sensibly completed each sentence, but in the second part, they were to complete the sentence with a word that did not make sense. They were penalized if answers were sensible completions of, or semantically related to words in, the sentence. An overall score based on response latency and response suppression was calculated (see Burgess \& Shallice, 1997).

Stop signal paradigm. On this version of the task (e.g., Logan, Schachar, \& Tannock, 1997), the participants reacted as quickly as possible to the letters $X$ and $O$, presented in the center of the computer screen for $1,000 \mathrm{msec}$, by pressing an appropriately marked key on the keyboard. If, however, the participants heard a stop signal (a 100msec, $1000-\mathrm{Hz}$ tone emitted by the computer on $25 \%$ of trials), they were to inhibit their keypresses. There were 256 test trials, each separated by a 500-msec interval, divided into eight 32-trial blocks. The participants were told before the task, and were reminded halfway through, that they would not always be able to inhibit their responses during the stop signal because it occurred randomly and infrequently. They were further warned not to wait for the stop signal before pressing a key on each trial. The delay between the visual stimulus and the stop signal was initially set for $250 \mathrm{msec}$. If the participants failed to inhibit their responses during a stop signal trial, the delay was decreased by $50 \mathrm{msec}$; if they successfully inhibited their responses, the delay was increased by $50 \mathrm{msec}$. The index of inhibition, stop signal reaction time, was calculated for each participant by subtracting the mean delay of the stop signal from the mean reaction time to the visual stimuli (see Logan et al., 1997).

\section{Procedure}

A departmental and a university review board approved the study, and the participants gave informed consent. Stimulus presentation and response recording during the PDP used Superlab Pro software (1997) on a personal computer. The participants were seated in front of the computer, were told that they would see two lists of words, and were asked to rate the pleasantness of each word aloud (on a scale of $1=$ low to $5=h i g h$ ). No mention of the subsequent memory test was made. Words appeared approximately $2 \mathrm{~cm}$ tall at the center of the screen in Times New Roman font and were presented for $2 \mathrm{sec}$ each, with a 500-msec interstimulus interval. At the end of the first study list, the participants were reminded they had just seen the first of two lists. They then pressed the space bar to view the second list, which was presented in the same way as the first. The interlist interval was approximately $10 \mathrm{sec}$. Upon completion of the study phase, the participant received either an inclusion or an exclusion test. Prior to each test, the administrator read the instructions aloud from the screen and placed a copy of the appropriate instructions in front of the participant. In the inclusion test, the participants were asked to press the $Y$ key if they had seen the word while making the pleasantness ratings and the $N$ key if it was a new word. Instructions for the exclusion test phase were identical, with the exception that people were asked to press $Y$ only to words from one of the lists (which was specified) and to press $N$ if the word was from the other list or was a new word. The order of the study lists, the pairings of target and distractor lists, whether the first or the second study list was excluded, and whether inclusion or exclusion was performed first at test were counterbalanced. Upon completion, the young adults were debriefed and given credit. The older adults were administered the additional inhibitory measures in the order listed above, before being debriefed and paid. The session took approximately $20 \mathrm{~min}$ for the young adults and $2 \mathrm{~h}$ (including a short break, if necessary) for the older adults.

\section{RESULTS}

We used one-way ANOVAs $(\alpha=.05)$ to compare older adults in the high-FL and low-FL groups with young people and to compare older adults in the high-MTL and lowMTL groups with the young group. ${ }^{3}$ Bonferroni independent $t$ tests were conducted, if necessary, to assess the

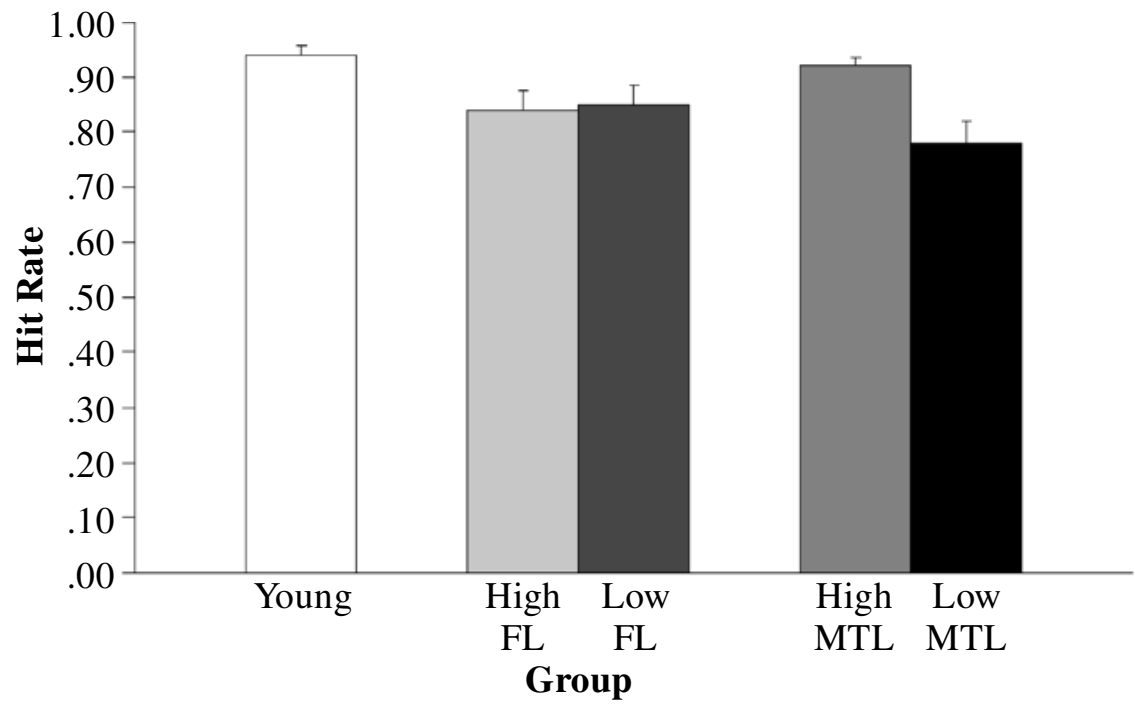

Figure 1. Mean inclusion hit rates $(+S E s)$ for young people and for older adults divided by FL function and MTL function. 


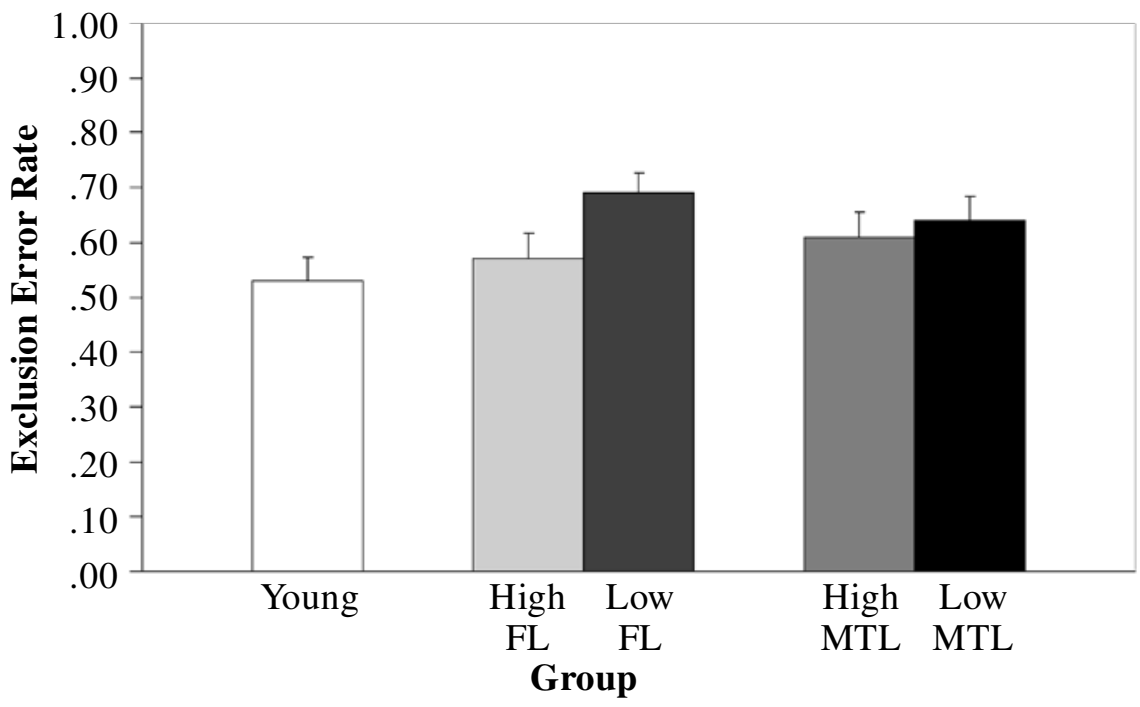

Figure 2. Mean exclusion error rates $(+S E s)$ for young people and for older adults divided by FL function and MTL function.

locus of group differences ( $\alpha=.017$ to adjust for multiple comparisons).

\section{Hit, Exclusion Error, \\ and New False Alarm Rates}

Figure 1 shows inclusion hit rates for the young people and for the older adults grouped by their FL scores (high/ low) and MTL scores (high/low). When younger adults were compared with older adults divided by FL group, there was an overall significant difference in hit rates across the three groups $\left[F(2,77)=3.48, M S_{\mathrm{e}}=0.02, p=.04\right]$. Older adults in the low-FL $(M=.85)$ and high-FL $(M=$ $.84)$ groups were equivalent to one another $(t<1)$, and both had lower hit rates than did the young people $[M=$ $.94 ; t(54)=2.35, p=.02$, and $t(54)=2.55, p=.02$, respectively]. We also compared young people with older adults grouped by MTL function. This analysis also yielded an overall group difference $[F(2,77)=11.09$, $\left.M S_{\mathrm{e}}=0.02, p<0.001\right]$. In this case, older adults in the lowMTL group $(M=.78)$ had reliably lower hit rates than did the high-MTL group $[M=.92 ; t(46)=3.19, p=.003]$, which did not differ from the young group $(M=.94 ; t<1)$.

Figure 2 shows exclusion error rates. When the older adults were divided by FL function, a significant difference was found among groups $\left[F(2,77)=3.83, M S_{\mathrm{e}}=\right.$ $0.05, p=.03]$. Only the low-FL older adults $(M=.69)$ were impaired relative to the young people, however $[M=.53$; $t(54)=2.75, p=.008]$. The high-FL group $(M=.57)$ made a number of exclusion errors similar to that of the young group $(t<1)$. MTL status appeared to have no bearing on exclusion errors: A one-way ANOVA indicated no differences in exclusion error rates among the young people, the low-MTL $(M=.64)$, and the high-MTL $(M=.61)$ groups of older adults $\left[F(2,77)=1.88, M S_{\mathrm{e}}=0.05, p>.05\right]$.
False alarms to new words, shown in Figures $3 \mathrm{~A}$ and $3 \mathrm{~B}$, were also analyzed. We combined the false alarm rates from the two test phases within subjects for our statistical comparisons, because preliminary analyses $(3 \times 2 \mathrm{mixed}$ ANOVAs, with FL or MTL group as the between-subjects variable and test phase [inclusion/exclusion] as the withinsubjects variable) showed no reliable differences between test phases and no interactions between test phase and FL function or MTL function $\left(F_{\mathrm{S}} \leq 1.31\right)$. A one-way ANOVA with FL group (young, high FL, low FL) as the betweensubjects variable indicated that the false alarm rate differed among FL groups $\left[F(2,77)=5.68, M S_{\mathrm{e}}=0.008\right.$, $p=.005]$. The low-FL group $(M=.13)$ made significantly more false alarms than did the young people $[M=$ $.05 ; t(54)=3.31, p=.002]$. No other group differences were reliable. A one-way ANOVA with MTL group (young, high-MTL, low-MTL) as the between-subjects variable also indicated a reliable difference $[F(2,77)=$ $\left.5.15, M S_{\mathrm{e}}=0.008, p=.008\right]$; the only significant difference in false alarms to new words was between the lowMTL group $(M=.13)$ and the young people $[t(54)=$ $3.49, p=.001]$.

\section{Recollection and Familiarity}

Estimates of recollection and familiarity were calculated according to the Yonelinas, Regehr, and Jacoby (1995) model. ${ }^{4}$ To correct for floor or ceiling effects in either hit or false alarm rates, values of $1 /(2 N)$ and $1-1 /(2 N)$ were substituted for scores of .00 and 1.00, respectively (Macmillan \& Creelman, 1991).

Recollection scores are shown in Figure 4. A one-way ANOVA with FL group (young, high FL, low FL) as the between-subjects variable revealed a significant difference among groups $\left[F(2,77)=4.69, M S_{\mathrm{e}}=0.05, p=\right.$ 

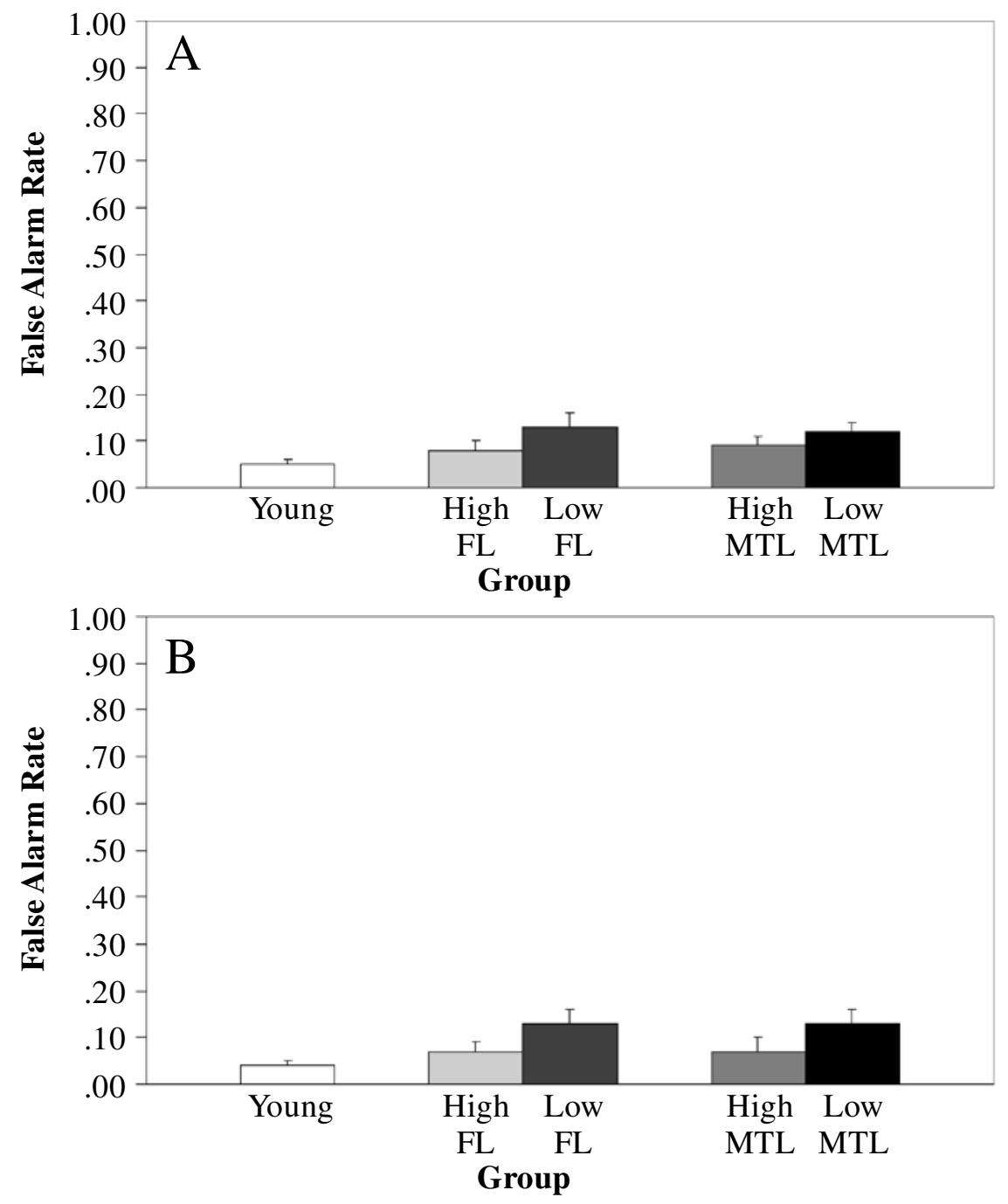

Figure 3. Mean false alarm rates $(+S E s)$ in the inclusion $(A)$ and exclusion $(B)$ test phases for young people and for older adults divided by FL function and MTL function.

.01]. Only the low-FL group $(M=.18)$, however, had lower recollection scores than did the young group $[M=$ $.37 ; t(54)=3.24, p=.002]$. A similar pattern was revealed for the comparison by MTL function. There was an overall significant group difference $\left[F(2,77)=4.17, M S_{\mathrm{e}}=0.05\right.$, $p=.02]$, and only the low-MTL group $(M=.19)$ was impaired relative to the young $[t(54)=2.89, p=.006]$.

In contrast to recollection, familiarity scores were reliably related only to the measure of MTL function in older adults (see Figure 5). Although the one-way ANOVA with FL group (young, high FL, low FL) as the betweensubjects variable suggested a reliable difference among groups $\left[F(2,77)=3.52, M S_{\mathrm{e}}=0.92, p=.03\right]$, none of the paired contrasts obtained significance $(t \mathrm{~s} \leq 2.15)$, and importantly, the high-FL group $(M=2.45)$ and the low-FL group $(M=2.40)$ had similar familiarity scores. A different pattern emerged when the older adults were divided in terms of MTL function $\left[F(2,77)=5.36, M S_{\mathrm{e}}=0.89, p=\right.$ $.007]$. The low-MTL group $(M=2.18)$ had a significantly lower estimate of familiarity than did the high-MTL group $[M=2.68 ; t(46)=2.82, p=.007]$, who were comparable to the young group $[M=3.01 ; t(54)=1.17]$.

\section{Inhibitory Measures and Recollection}

Older adults' scores from the inhibitory tasks were entered into bivariate Pearson correlations with the results from the PDP. None of the inhibitory measures reliably predicted exclusion error rates $(p s>.07)$ or recollection scores $(p s>.17)$. We also constructed a composite measure of inhibition, based on the average of older adults' $z$ scores from the inhibitory tasks, which failed to reliably predict exclusion error rates or recollection scores.

\section{DISCUSSION}

This is the first study of which we are aware that has examined the relationship between FL and MTL function and performance on the PDP in normal aging. Poor per- 


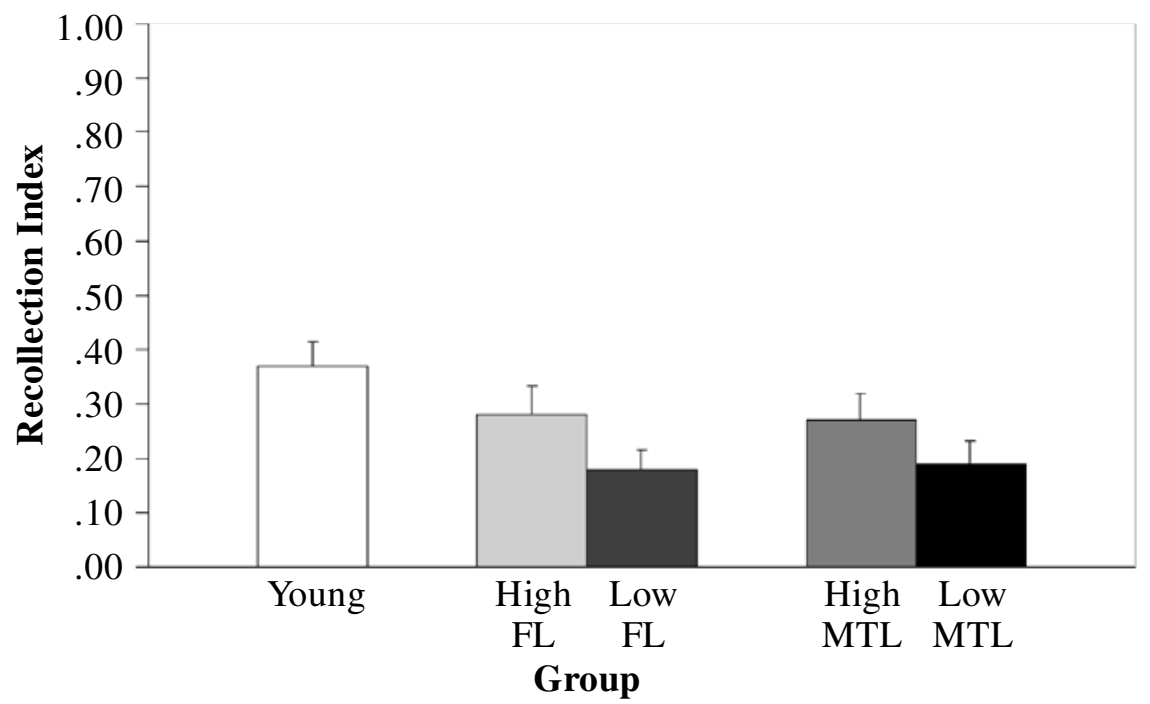

Figure 4. Mean recollection index $(+S E)$ for young people and for older adults divided by FL function and MTL function. Recollection was calculated by using the algorithm from Yonelinas, Regehr, and Jacoby (1995).

formance on the PDP does not seem to be an obligatory aspect of aging. Instead, performance varied among the older adults, depending on neuropsychological status. Recollection appeared to be supported in older adults by both FL and MTL function, whereas familiarity appeared to be associated primarily with MTL status.

\section{FL and MTL Status and the PDP}

The aggregate scores of FL and MTL function were differentially related to hit, exclusion error, and false alarm rates in older adults. Hit rates were higher in the high-MTL group than in the low-MTL group of older adults but were not different between the FL groups. On the other hand, exclusion errors were associated with FL, but not with MTL, status, with only the low-FL group making significantly more exclusion errors than did young people. Older adults with low-FL function and those with low-MTL function were more likely than young people to make false alarms to new items. Perhaps more informative than the raw scores, however, were the indexes of recollection and familiarity, which were differentially related to FL and MTL status in the older adults.

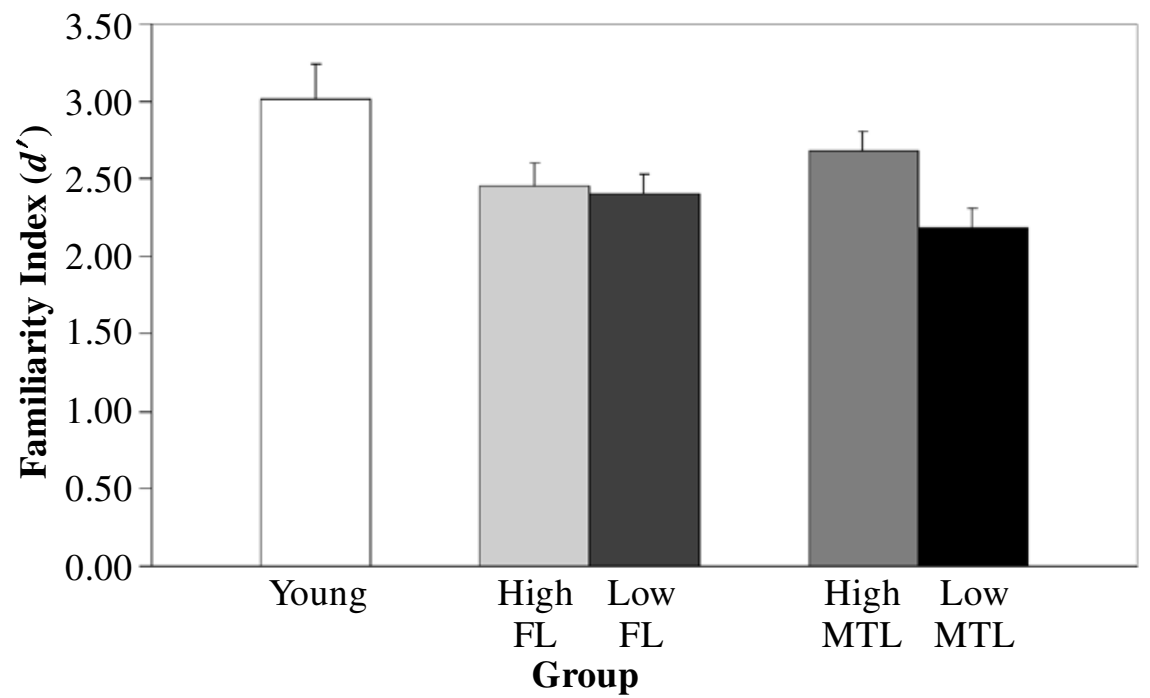

Figure 5. Mean familiarity index $(+S E)$ for young people and for older adults divided by FL function and MTL function. Familiarity was calculated by using the algorithm from Yonelinas, Regehr, and Jacoby (1995). 


\section{Recollection}

Previous research done with this paradigm has indicated diminished recollection with age (Hay \& Jacoby, 1999; Jennings \& Jacoby, 1993, 1997; Rybash \& Hoyer, 1996; Rybash et al., 1998; Salthouse et al., 1997; SchmitterEdgecombe, 1999; Titov \& Knight, 1997; for a review, see Light et al., 1999), but we found that not all older adults were impaired in recollection. Relative to young people, recollection scores were impaired only in the low-FL and the low-MTL groups of older adults, providing support for both the FL and the MTL hypotheses outlined in the introduction. This result is only partly consistent with previous studies in our lab, in which we found that FL, but not MTL, status affected source memory, whereas MTL, but not FL, status affected item memory in older adults (Glisky et al., 1995). A critical difference between those studies and the present one, however, is that in those paradigms, we separated the source and item memory tests, so that source memory decisions were independent of item memory decisions. In the present task, on the other hand, judgments in the exclusion task (and thus recollection) required the conjunction in memory of an item decision (i.e., studied vs. unstudied) and a source decision (i.e., List 1 vs. List 2), which, according to the previous studies, are mediated by MTL and FL function, respectively. Henkel et al. (1998) reported a similar outcome in a yes/no source memory paradigm in which the item and the source memory decisions were combined. Their results also indicated that both FL and MTL function were related to source memory performance when source and item judgments were coupled.

What is the nature of the FLs' involvementin contextual memory tasks? At least two possibilities exist. It could be that good FL function supports the spontaneous integration of item (e.g., word) and source (e.g., list) information at encoding. Glisky et al. (2001), using a perceptual sourcemonitoring paradigm, showed that low-FL older adults were impaired relative to high-FL older adults and young people on a source memory test. Yet, when low-FL participants were given an encoding task that encouraged integration of item and source, they performed as well as high-FL participants and young people did. This suggests that under normal circumstances, older adults with poor FL function might not spontaneously integrate item and source information at encoding and, thus, would perform poorly on tests requiring memory for source. The increased tendency of older adults in the low-FL group to commit exclusion errors, reflecting the inability to remember list membership, is consistent with this explanation and might account for the reduced estimates of recollection in this group. Use of an integrative encoding task in a future PDP study might thus attenuate the differences between age and neuropsychological groups found here.

Alternatively, the FLs might search and/or monitor memory for the correct item-source match at retrieval. Evidence consistent with this possibility comes from a pair of source memory studies using event-related potentials in young people (Senkfor \& Van Petten, 1998; Van Petten, Senkfor, \& Newberg, 2000). In both studies, source memory decisions were accompanied by a large late positive component of the event-related response at prefrontal sites. There was no difference in the amplitude of the frontal effect between trials on which participants correctly identified the source and those on which they misattributed the source. Thus, this frontal response might reflect an attempt to retrieve the correct pairing of item and source information from memory or a decision about whether a correct match has been made (although see Jacoby, 1999, for an alternative account of the relation between content and context in recognition). A complementary finding with single-trial functional magnetic resonance imaging was reported by Henson, Shallice, and Dolan (1999). They reported that the FLs (among other regions) were more active during the exclusion phase than during the inclusion phase of a PDP task, possibly owing to the increased need to monitor information about temporal context during the exclusion test. Such search and decision processes, likely mediated by the frontal cortex, might have been involved in the exclusion test in the present study.

As was noted previously, other processes - for example, inhibition - might also be important for recollection. Graf and Komatsu (1994) and Zacks et al. (1999) proposed that a failure to inhibit the familiarity process during the exclusion test might explain PDP errors. Yet, in the present data set, there was no indication of a relationship between recollection and the specific inhibitory measures, suggesting that the ability to inhibit the sense of familiarity at retrieval might not be a key factor in PDP performance. Intercorrelations among inhibitory tasks in older adults are often low, however (e.g., Kramer et al., 1994), so one must be cautious in concluding that there is no relationship between inhibition and recollection. The kinds of inhibition measured by the psychometric tests in the present study might simply be different from those required in the PDP.

\section{Familiarity}

Decreased familiarity with age has been reported by some researchers using the PDP (Light et al., 1999; Rybash et al., 1998; Schmitter-Edgecombe, 1999), but others have found no age-related changes in that score (Hay \& Jacoby, 1999; Jennings \& Jacoby, 1993, 1997; Salthouse et al., 1997; Titov \& Knight, 1997). In the present study, only the older adults with low-MTL status exhibited lower familiarity scores than did the young people. The measure of FL function had no reliable influence on familiarity. These results suggest that individual differences in MTL function are important for the ability to use familiarity during a recognition memory task, and these individual differences may account for the dispute in the literature over whether age-related changes in familiarity occur. Other possible reasons for the varying results in the literature include differences in the tasks or process dissociation formulae used across studies and the degree to which people make exclusion errors. If participants do not make 
exclusion errors, as sometimes occurs in young people, their level of familiarity will be underestimated, and age differences will thereby be reduced (Jacoby, 1991; Rybash et al., 1998; Schmitter-Edgecombe, 1999). Yet it appears that even when all participants make such errors, as in the present study, only those older adults with low-MTL function are impaired in familiarity.

Both the familiarity index and the tests that make up the current MTL battery reflect the ability to remember that an item was recently encountered. This is arguably independent of the ability to make more precise judgments about the context in which the item was studied (Atkinson \& Juola, 1974; Jacoby, 1991; Jacoby \& Dallas, 1981; Mandler, 1980). Judgments based on familiarity may not be completely context free, of course: In familiarity-based judgments in the present study, people likely remembered some information about the place where (on the computer screen in the laboratory) and time when (during the last few minutes) they had seen the item. Similarly, some of the tests that make up the current MTL score require memory for aspects of context (e.g., in the WMS-R paired associates tasks). In general, however, the demands on memory for context reflected in the familiarity index and in the MTL factor score appear to be relatively low.

The relation between the familiarity index and the MTL factor score suggests that familiarity and the tests that make up the current MTL battery rely on similar (or adjacent) brain regions. The present neuropsychologicalbattery is unable, however, to address specifically the question of functional specialization within the medial temporal system raised by Aggleton and Brown (1999), because it is currently unknown whether the MTL factor is dependent on specific medial temporal regions. Gabrieli, Brewer, Desmond, and Glover (1997) conducted a functional neuroimaging study related to the question of specialization of memory processes in different subregions of the MTLs. By comparing encoding of novel versus repeated pictures, they found greater activation in the parahippocampal cortex for the former, which they attributed to a difference in the familiarity of the two sets of stimuli. To address this question further, we are presently conducting a volumetric analysis of MRIs of the brains of our older participants and examining the extent to which regional brain volumes are correlated with the composite neuropsychological scores of FL and MTL functions. In the meantime, a PDP study that compares patients having selective hippocampal lesions with those having damage to the perirhinal cortex would be particularly useful to evaluate further the Aggleton and Brown hypothesis about regional specificity within the MTL system.

Several versions of the PDP exist other than the one used in the present study, and all rely on a similar underlying logic. It might thus be fruitful to explore whether the pattern of results in the present study would be obtained in other PDP paradigms, particularly those that involve several within-subjects to-be-excluded lists (e.g., Yonelinas, 1994) or eliminate the need to correct for false alarms (e.g., Hay \& Jacoby, 1999). A potential problem with the list discrimination paradigm is that people may be able to recollect some contextual features of the study episode without recollecting temporal context. This partial recollection of noncritical information from the study episode may influence estimates of recollection and familiarity (e.g., Dodson \& Johnson, 1996; Yonelinas \& Jacoby, 1996). This problem may be unavoidable, however, given that recollection is usually measured in the PDP on the basis of one critical feature from the study phase (e.g., List $1 /$ List 2, large/small font, read/heard, etc.).

In summary, older adults were not all equally likely to make memory errors in the PDP. Instead, those with lowFL function were more likely to make exclusion errors, indicating an inability to recollect list membership, although they were not impaired in their ability to recognize targets, which could be accomplished on the basis of familiarity. Those with low-MTL function, however, appeared to be impaired in item recognition, a task that likely relies heavily on familiarity judgments. The present data regarding recollection and familiarity are compatible with Moscovitch's (1994) working with memory model of episodic memory, especially with its description of retrieval. According to the model, if presented with an effective memory cue during retrieval, the MTLs deliver information to the FLs about an item's previous occurrence in an obligatory, automatic manner. It is then up to the FLs to search memory and make a decision about the temporal context in which the item appeared. In the present study, judging whether a particular item had been encountered before could be based on familiarity alone, arguably requiring only MTL processes. On the other hand, recollection involved remembering both the item and its list membership, possibly relying on processes mediated by both the MTLs and the FLs. FL and MTL processes appear to play different roles in recognition memory and seem to be differentially involved, depending on the extent to which recognition of context is important.

\section{REFERENCES}

Aggleton, J. P., \& Brown, M. W. (1999). Episodic memory, amnesia, and the hippocampal-anterior thalamic axis. Behavioral \& Brain Sciences, 22, 425-489.

Aggleton, J. P., \& Shaw, C. (1996). Amnesia and recognition memory: A reanalysis of psychometric data. Neuropsychologia, 34, 51-62.

Atkinson, R. C., \& Juola, J. F. (1974). Search and decision processes in recognition memory. In D. H. Krantz, R. C. Atkinson, R. D. Luce, \& P. Suppes (Eds.), Contemporary developments in mathematical psychology: Vol. 1. Learning, memory, \& thinking (pp. 242-293). San Francisco: Freeman.

Buchner, A., Steffens, M. C., Erdfelder,E, \& Rothregel, R (1997). A multinomial model to assess fluency and recollection in a sequence learning task. Quarterly Journal of Experimental Psychology, 50A, 631-663.

Burgess, P. W., \& Shallice, T. (1996). Response suppression, initiation and strategy use following frontal lobe lesions. Neuropsychologia, 34, 263-273.

Burgess, P. W., \& Shallice, T. (1997). The Hayling and Brixton Tests. Bury St. Edmunds, U.K.: Thames Valley Test Company.

Butters, M. A., Kaszniak, A. W., Glisky, E. L., Eslinger, P. J., \& 
Schacter, D. L. (1994). Recency discrimination deficits in frontal lobe patients. Neuropsychology, 8, 343-353.

Cabeza, R, Anderson, N. D., Houle, S., Mangels, J. A., \& Nyberg, L. (2000). Age-related differences in neural activity during item and temporal-order memory retrieval: A positron emission tomography study. Journal of Cognitive Neuroscience, 12, 197-206.

Cabeza, R., Mangels, J., Nyberg, L., Habib, R., Houle, S., McInTOSH, A. R. \& Tulving, E. (1997). Brain regions differentially involved in remembering what and when: A PET study. Neuron, 19, 863870 .

Cermak, L. S., Verfaellie, M., Sweeney, M., \& Jacoby, L. L. (1992). Fluency versus conscious recollection in the word completion performance of amnesic patients. Brain \& Cognition, 20, 367-377.

Christensen, H., Kopelman, M. D., Stanhope, N., Lorentz, L., \& Owen, P. (1998). Rates of forgetting in Alzheimer dementia. Neuropsychologia, 36, 547-557.

Craik, F. I. M., Morris, L. W., Morris, R. G., \& Loewen, E. R. (1990). Relations between source amnesia and frontal lobe functioning in older adults. Psychology \& Aging, 5, 148-151.

Delis, D. C., Kramer, J. H., Kaplan, E., \& Ober, B. A. (1987). California Verbal Learning Test. New York: Psychological Corporation.

Dodson, C. S., \& Johnson, M. K. (1996). Some problems with the process-dissociation approach to memory. Journal of Experimental Psychology: General, 125, 181-194.

Dorfman, J., Wagner, A. D., Stebbins, G. T., Dirksen, C., Turner, D., Glover, G. H., Desmond, J. E., \& Gabrieli, J. D. E. (1998). Recognition memory in the inclusion-exclusion paradigm: An fMRI study. Journal of Cognitive Neuroscience, 51 (Suppl. 5), 51.

DYWAN, J., \& JACOBY, L. (1990). Effects of aging on source monitoring: Differences in susceptibility to false fame. Psychology \& Aging, 5, 379-387.

Fabiani, M., \& Friedman, D. (1997). Dissociations between memory for temporal order and recognition memory in aging. Neuropsychologia, 35, 129-141.

Feldman, M. J. \& Drasgow, J. (1981). The Visual-Verbal Test manual. Los Angeles: Western Psychological Services.

Folstein, M. F., Folstein, S. F., \& McHugh, P. R. (1975). "Mini-mental state": A practical method for grading the cognitive state of patients for the clinician. Journal of Psychiatric Research, 12, 189-198.

FrANCIS, W. N., \& KuČERA, H. (1982). Frequency analysis of English usage: Lexicon and grammar. Boston: Houghton Miffin.

Gabrieli, J. D. E., Brewer, J. B., Desmond, J. E., \& Glover, G. H. (1997). Separate neural bases of two fundamental memory processes in the human medial temporal lobe. Science, 276, 264-266.

Glisky, E. L., Polster, M. R., \& Routhieaux, B. C. (1995). Double dissociation between item and source memory. Neuropsychology, 9, 229235.

Glisky, E. L., Rubin, S. R., \& DAvidson, P. S. R. (2001). Source memory in older adults: An encoding or retrieval problem? Journal of Experimental Psychology: Learning, Memory, \& Cognition, 27, 1131-1146.

Graf, P., \& Komatsu, S. (1994). Process Dissociation Procedure: Handle with caution. European Journal of Cognitive Psychology, 6, 113-129.

Hart, R. P., Kwentus, J. A., Wade, J. B., \& Tay lor, J. R. (1988). Modified Wisconsin Card Sorting Test in elderly normal, depressed, and demented patients. Clinical Neuropsychologist, 2, 49-56.

HAY, J. F., \& JACOBY, L. L. (1999). Separating habit and recollection in young and older adults: Effects of elaborative processing and distinctiveness. Psychology \& Aging, 14, 122-134.

Hay, J. F., Moscovitch, M., \& Levine, B. (2002). Dissociating habit and recollection: Evidence from Parkinson's disease, amnesia, and focal lesion patients. Neuropsychologia, 40, 1324-1334.

Henkel, L. A., Johnson, M. K., \& De Leonardis, D. M. (1998). Aging and source monitoring: Cognitive processes and neuropsychological correlates. Journal of Experimental Psychology: General, 127, 251-268.

Henson, R. N. A., Shallice, T., \& Dolan, R. J. (1999). Right prefrontal cortex and episodic memory retrieval: A functional MRI test of the monitoring hypothesis. Brain, 122, 1367-1381.

JACOBY, L. L. (1991). A process dissociation framework: Separating automatic from intentional uses of memory. Journal of Memory \& Language, 30, 513-541.
JACOBY, L. L. (1999). Ironic effects of repetition: Measuring age-related differences in memory. Journal of Experimental Psychology: Learning, Memory, \& Cognition, 25, 3-22.

JACOBY, L. L., \& DALlas, M. (1981). On the relationship between autobiographical memory and perceptual learning. Journal of Experimental Psychology: General, 110, 306-340.

JACOBY, L. L., JENNINGS, J. M., \& HAY, J. F. (1997). Dissociating automatic and consciously controlled processes: Implications for diagnosis and rehabilitation of memory deficits. In D. J. Herrmann, M. K. Johnson, C. L. McEvoy, C. Hertzog, \& P. Hertel, (Eds.), Basic and applied memory research: Theory in context (pp. 161-192). Hillsdale, NJ: Erlbaum.

Jacoby, L. L., Yonelinas, A. P., \& Jennings, J. M. (1997). The relation between conscious and unconscious (automatic) influences: A declaration of independence. In J. D. Cohen \& J. W. Schooler (Eds.), Scientific approaches to consciousness (pp. 13-47). Mahwah, NJ: Erlbaum.

JENNINGS, J. M., \& JACOBY, L. L. (1993). Automatic versus intentional uses of memory: Aging, attention, and control. Psychology \& Aging, 8, 283-293.

JENNINGS, J. M., \& JACOBY, L. L. (1997). An opposition procedure for detecting age-related deficits in recollection: Telling effects of repetition. Psychology \& Aging, 12, 352-361.

Johnson, M. K., O'Connor, M., \& CAnToR, J. (1997). Confabulation, memory deficits, and frontal dysfunction. Brain \& Cognition, 34, 189206.

Joordens, S., \& Merikle, P. M. (1993). Independence or redundancy: Two models of conscious and unconscious influences. Journal of Experimental Psychology: General, 122, 462-467.

Kazes, M., Berthet, L., Danion, J. M., Amado, I., Willard, D., Robert, P., \& Poirier, M. F. (1999). Impairment of consciously controlled use of memory in schizophrenia. Neuropsychology, 13, 54-61.

Kesner, R. P., Hopkins, R. O., \& Fineman, B. (1994). Item and order dissociation in humans with prefrontal damage. Neuropsychologia, 32, 881-891

KLIEGL, R, \& Lindenberger, U. (1993). Modeling intrusions and correct recall in episodic memory: Adult age differences in encoding of list context. Journal of Experimental Psychology: Learning, Memory, \& Cognition, 19, 617-637.

Kopelman, M. D., Stanhope, N., \& Kingsley, D. (1997). Temporal and spatial context memory in patients with focal frontal, temporal lobe, and diencephalic lesions. Neuropsychologia, 35, 1533-1545.

Kramer, A. F., Humphrey, D. G., Larish, J. F., \& Logan, G. D. (1994). Aging and inhibition: Beyond a unitary view of inhibitory processing in attention. Psychology \& Aging, 9, 491-512.

LEZAK, M. D. (1995). Neuropsychological assessment (2nd ed.). New York: Oxford University Press.

Light, L. L., Prull, M. W., La Voie, D. J., \& Healy, M. R. (1999). Dual-process theories of memory in old age. In T. J. Perfect \& E. A. Maylor (Eds.), Models of cognitive aging (pp. 238-300). Oxford: Oxford University Press.

Logan, G. D., Schachar, R. J., \& Tannock, R. (1997). Impulsivity and inhibitory control. Psychological Science, 8, 60-64.

Macmillan, N. A., \& Creelman, C. D. (1991). Detection theory: A user's guide. New York: Cambridge University Press.

MANDLER, G. (1980). Recognizing: The judgment of previous occurrence. Psychological Review, 87, 252-271.

MANGELS, J. A. (1997). Strategic processing and memory for temporal order in patients with frontal lobelesions. Neuropsychology, 11, 207-221.

Mather, M., Johnson, M. K., \& De Leonardis, D. M. (1999). Stereotype reliance in source monitoring: Age differences and neuropsychological test correlates. Cognitive Neuropsychology, 16, 437-458.

Mayes, A. R, VAN EiJK, R., \& IsaAc, C. L. (1995). Assessment of familiarity and recollection in the false fame paradigm using a modified process dissociation procedure. Journal of the International Neuropsychological Society, 1, 469-482.

McAndrews, M. P., \& Milner, B. (1991). The frontal cortex and memory for temporal order. Neuropsychologia, 29, 849-859.

Milner, B., Corsi, P., \& Leonard, G. (1991). Frontal-lobe contribution to recency judgements. Neuropsychologia, 29, 601-618.

Moscovitch, M. (1994). Memory and working with memory: Evalua- 
tion of a component process model and comparisons with other models. In D. L. Schacter \& E. Tulving (Eds.), Memory systems 1994 (pp. 269-310). Cambridge, MA: MIT Press.

Mulligan, N. W., \& Hirshman, E. (1997). Measuring the bases of recognition memory: An investigation of the process-dissociation framework. Journal of Experimental Psychology: Learning, Memory, \& Cognition, 23, 280-304.

Multhaup, K. S. (1995). Aging, source, and decision criteria: When false fame errors do and do not occur. Psychology \& Aging, 10, 492-497.

Nyberg, L., McIntosh, A. R., Cabeza, R., Habib, R., Houle, S., \& Tulving, E. (1996). General and specific brain regions involved in encoding and retrieval of events: What, where, and when. Proceedings of the National Academy of Sciences, 93, 11280-11285.

Parkin, A. J., Leng, N. R. C., Stanhope, N., \& Smith, A. P. (1988). Memory impairment following ruptured aneurysm of the anterior communicating artery. Brain \& Cognition, 7, 231-243.

Parkin, A. J., Walter, B. M., \& Hunkin, N. (1995). Relationships between normal aging, frontal lobe function, and memory for temporal and spatial information. Neuropsychology, 9, 304-312.

Ratcliff, R., Van Zandt, T., \& McKoon, G. (1995). Process dissociation, single-process theories, and recognition memory. Journal of Experimental Psychology: General, 124, 352-374.

RAz, N. (2000). Aging of the brain and its impact on cognitive performance: Integration of structural and functional findings. In F. I. M. Craik \& T. A. Salthouse (Eds.), Handbook of aging and cognition (2nd ed., pp. 1-90). Mahwah, NJ: Erlbaum.

Reitan, R. M. (1992). Trail Making Tests. Tucson, AZ: Reitan Neuropsychology Laboratory.

Rempel-Clower, N., Zola, S. M., Squire, L. R., \& Amaral, D. G. (1996). Three cases of enduring memory impairment following bilateral damage limited to the hippocampal formation. Journal of Neuroscience, 16, 5233-5255.

Roediger, H. L., III, \& McDermott, K. (1994). The problem of differing false-alarm rates for the process dissociation procedure: Comments on Verfaellie and Treadwell (1993). Neuropsychology, 8, 284-288.

Rybash, J. M., \& Hoyer, W. J. (1996). Process dissociation procedure reveals age differences in unconscious influences on memory for possible and impossible objects. Aging, Neuropsychology, \& Cognition, 3, 251-263.

Rybash, J. M., Santoro, K. E., \& Hoyer, W. J. (1998). Adult age differences in conscious and unconsciousinfluences on memory for novel associations. Aging, Neuropsychology, \& Cognition, 5, 14-26.

Salthouse, T. A., Toth, J. P., Hancock, H. E., \& Woodard, J. L. (1997). Controlled and automatic forms of memory and attention: Process purity and the uniqueness of age-related influences. Journal of Gerontology: Psychological Sciences, 52B, 216-228.

Scarrabelotti, M., \& Carroll, M. (1999). Memory dissociation and metamemory in multiple sclerosis. Neuropsychologia, 37, 1335-1350.

Schmitter-EDGecombe, M. (1999). Effects of divided attention and time course on automatic and controlled components of memory in older adults. Psychology \& Aging, 14, 331-345.

Senkfor, A. J., \& VAn Petten, C. (1998). Who said what? An eventrelated potential investigation of source and item memory. Journal of Experimental Psychology: Learning, Memory, \& Cognition, 24, 10051025.

Shimamura, A. P., Janowsky, J. S., \& Squire, L. R. (1990). Memory for the temporal order of events in patients with frontal lobe lesions and amnesic patients. Neuropsychologia, 28, 803-813.

SPencer, W. D., \& Raz, N. (1995). Differential effects of aging on memory for content and context: A meta-analysis. Psychology \& Aging, 10, 527-539.

Spreen, O., \& Benton, A. L. (1977). Neurosensory Center Comprehensive Examination for Aphasia (NCCEA) (Rev. ed.). Victoria, BC: University of Victoria Neuropsychology Laboratory.

Steffens, M. C., Buchner, A., Martensen, H., \& Erdfelder, E. (2000). Further evidence on the similarity of memory processes in the process dissociation procedure and in source monitoring. Memory \& Cognition, 28, 1152-1164.

Ste-Marie, D. M., Jennings, J. M., \& Finlayson, A. J. (1996). Process dissociation procedure: Memory testing in populations with brain damage. Clinical Neuropsychologist, 10, 25-36.
Superlab Pro (1997). San Pedro, CA: Cedrus Corp.

Swain, S. A., Polkey, C. E., Bullock, P., \& Morris, R. G. (1998). Recognition memory and memory for order in script-based stories following frontal lobe excisions. Cortex, 34, 25-45.

Titov, N., \& KNight, R. G. (1997). Adult age differences in controlled and automatic memory processing. Psychology \& Aging, 12, 565-573.

Toth, J. P., \& Hunt, R. R. (1998). Not one versus many, but zero versus any: Structure and function in the context of the multiple memory systems debate. In J. K. Foster \& M. Jelicic (Eds.), Memory: Systems, process, or function? (pp. 232-272). Oxford: Oxford University Press.

Trenerry, M. R., Crosson, B., DeBoe, J., \& Leber, W. R. (1989). The Stroop Neuropsychological Screening Test. Odessa, FL: Psychological Assessment Resources.

Van Petten, C., Senkfor, A. J., \& Newberg, W. M. (2000). Memory for drawings in locations: Spatial source memory and event-related potentials. Psychophysiology, 37, 551-564.

VERfAELlie, M. (1994). A re-examination of recognition memory in amnesia: Reply to Roediger and McDermott. Neuropsychology, 8, 289292.

Verfaellie, M., \& Treadwell, J. R. (1993). Status of recognition memory in amnesia. Neuropsychology, 7, 5-13.

WECHSLER, D. (1981). Wechsler Adult Intelligence Scale-Revised manual. New York: Psychological Corporation.

WeCHSLER, D. (1987). Wechsler Memory Scale-Revised manual. New York: Psychological Corporation.

WeCHSLER, D. (1997a). Wechsler Adult Intelligence Scale-III. San Antonio, TX: Harcourt Brace, Psychological Corporation.

WeChSLER, D. (1997b). Wechsler Memory Scale-III. San Antonio, TX: Harcourt Brace, Psychological Corporation.

Wechsler Abbreviated Scale of Intelligence (1999). San Antonio, TX: Harcourt Brace, Psychological Corporation.

Yonelinas, A. P. (1994). Receiver-operating characteristics in recognition memory: Evidence for a dual-process model. Journal of Experimental Psychology: Learning, Memory, \& Cognition, 20, 1341-1354.

Yonelinas, A. P. (2001). Components of episodic memory: The contribution of recollection and familiarity. Philosophical Transactions of the Royal Society of London: Series B, 356, 1363-1374.

Yonelinas, A. P., Dobbins, I., Szymanski, M. D., Dhaliwal, H. S., \& KING, L. (1996). Signal-detection, threshold, and dual-process models of recognition memory: ROCs and conscious recollection. Consciousness \& Cognition, 5, 418-441.

Yonelinas, A. P., \& JAcoBy, L. L. (1996). Noncritical recollection: Familiarity as automatic, irrelevant recollection. Consciousness \& Cognition, 5, 131-141.

Yonelinas, A. P., Kroll, N. E., Dobbins, I., Lazzara, M., \& KNIGHT, R. T. (1998). Recollection and familiarity deficits in amnesia: Convergence of remember/know, process dissociation, and ROC data. Neuropsychology, 12, 323-339.

Yonelinas, A. P., Regehr, G., \& JACoby, L. L. (1995). Incorporating response bias in a dual-process theory of memory. Journal of Memory \& Language, 34, 821-835.

ZACKS, R. T., HASHER, L., \& LI, K. Z. H. (1999). Human memory. In F. I. M. Craik \& T. A. Salthouse (Eds.), Handbook of aging and cognition (2nd ed., pp. 293-357). Mahwah, NJ: Erlbaum.

Zola-Morgan, S., SQuire, L. R., \& Amaral, D. G. (1986). Human amnesia and the medial temporal region: Enduring memory impairment following a bilateral lesion limited to field CA1 of the hippocampus. Journal of Neuroscience, 6, 2950-2967.

\section{NOTES}

1. Although hippocampal lesions may be sufficient to impair performance on the kinds of tests that make up our current MTL measure (Rempel-Clower, Zola, Squire, \& Amaral, 1996;Zola-Morgan, Squire, \& Amaral, 1986), the contribution of the perirhinal cortex to performance of these tasks in humans is still unclear.

2. For some older adults who were tested using the Wechsler Memory Scale-III (1997b), a comparable score was used, the first recall (total) score from the Logical Memory I subtest.

3 . In all cases in which we compared young people with older adults divided by FL or the MTL function, we also conducted $2 \times 2$ ANOVAs 
to examine possible interactions between the FL and the MTL scores. In none of these analyses were the interactions reliable $\left(F_{\mathrm{S}} \leq 2.27\right)$.

4 . The algorithm is based on a dual-process model in which recollection is described as a threshold process and familiarity is described as a Gaussian signal detection process. This model incorporates into the process dissociation equations a measure of discriminability $\left(d^{\prime}\right)$ and a criterion for both the inclusion $\left(c_{\text {inc }}\right)$ and the exclusion $\left(c_{\text {exc }}\right)$ test phases. The discriminability measure represents how well people can discriminate between old and new items, and the criteria represent how liberal or conservative they are in their responses, with a more negative criterion indicating a more conservative response bias. In this model, the famil- iarity term $(F)$ is replaced by $\Phi\left(d^{\prime} / 2-c\right)$, where $\Phi$ represents the probability that an item's will familiarity exceed the criterion. Evidence supporting this model is reported by Yonelinas et al. (1995; Yonelinas, Dobbins, Szymanski, Dhaliwal, \& King, 1996; for a review, see Yonelinas, 2001). In the present study, recollection and familiarity were also calculated according to the two-high threshold model suggested by Roediger and McDermott (1994), which yielded a similar pattern of results.

(Manuscript received November 30, 2001; revision accepted for publication April 25, 2002.) 